\title{
The Results of the Surgical Treatment of Spontaneous Rhinorrhea via Craniotomy and the Contribution of CT Cisternography to the Detection of Exact Leakage Side of CSF
}

\author{
Abdulfettah TUMTURK ${ }^{1}$, Halil ULUTABANCA ${ }^{1}$, Abdulkerim GOKOGLU², Sukru ORAL ${ }^{3}$, Ahmet MENKU $^{1}$, \\ Ali KURTSOY ${ }^{1}$ \\ ${ }^{1}$ Erciyes University, Medical Faculty, Department of Neurosurgery, Kayseri, Turkey \\ ${ }^{2}$ Kastamonu State Hospital, Neurosurgery Clinic, Kastamonu, Turkey \\ ${ }^{3}$ Ministry of Health, Training and Research Hospital, Department of Neurosurgery, Kayseri, Turkey
}

\section{ABSTRACT}

AIM: To share the results of conventional surgery in rhinorrhea and the contribution of computerized tomography (CT) cisternography to determination of the site of cerebrospinal fluid (CSF) leak.

MATERIAL and METHODS: Twelve cases treated for spontaneous rhinorrhea were included in this study. All the cases underwent cranial CT and magnetic resonance imaging (MRI). CT cisternography was performed in four patients whose bone defect or leakage site could not be detected by CT and MRI. In order to repair the defect, either the galea or galea together with collagen matrix was used and the procedure was supported with fibrin glue.

RESULTS: In the cases, postoperative rhinorrhea was seen in neither the early nor the late follow up period. We observed no complications related to CT cisternography or craniotomy. The leakage area was successfully detected with CT cisternography when the other methods failed.

CONCLUSION: Bone defect can usually be shown by means of CT. However, when bone-defect cannot be shown or the dura in the defective area is intact, CT cisternography is useful to show the CSF leak. Conventional surgery was very succesful in the treatment of spontaneous rhinorrhea but it was cosmetically problematic. In the patients both treated with galea and galea together with collagen matrix, the repair of the defect was successful.

KEYWORDS: Spontaneous CSF fistula, Rhinorrhea, CT cisternography

\section{INTRODUCTION}

\section{C}

erebrospinal fluid (CSF) leak or cerebrospinal fistula is a medical condition described first by St. Clair Thomp-

son, in which the CSF leaks out of intracranial cavity due to the presence of defects in the dura on the skull base (1). It suggests a laceration or defect in the dura, arachnoid and pia mater, causing a communication between intracranial cavity and nasal or tympanic cavity (13). Cribriform plate is the area where CSF leak often occurs, followed in terms of frequency by sella, sphenoid, ethmoid and frontal sinuses $(7,29)$.
The majority of CSF leaks are posttraumatic $(80 \%)$ or postoperative/iatrogenic (16\%) and only $4 \%$ are spontaneous (2). Spontaneous or primary CSF fistulas have been accepted as a different entity, seen in patients without any known etiologic factors such as a tumor, trauma or congenital anomalies. It is generally seen in the middle-aged obese women $(10,20)$.

In the presence of a nasal secretion and a suspicion of CSF leak, the nasal fluid must be examined for the possibility of CSF. For this purpose, diagnostic procedures based on structural differences of bodily fluids are used in certain 
laboratories (18). Neuroradiological images are also crucial in the diagnosis of CSF leak. Computerized tomography (CT) or contrast-enhanced CT may confirm CSF leak and the exact place of the leakage (28). While magnetic resonance imaging (MRI) is effective in determining the abnormalities of some soft tissues like tumor and meningo-encephalocele, it is inefficient in showing bone fractures and defects $(6,13)$. The main goal of the surgical treatments performed in spontaneous rhinorrhea both extra-cranially and intra-cranially has been to repair the defect.

\section{- MATERIAL and METHODS}

In this retrospective study, we studied a total of 12 patients (5 male and 7 female) who were treated in our clinic for spontaneous rhinorrhea originating from the cribriform plate between June 2007 and June 2013. The mean age of the patients was 47.4 years (range: 21 to 68 years). The patients with a history of trauma, congenital anomaly and radiotherapychemotherapy, and iatrogenic cases were excluded. The patients underwent a complete neurological examination, specifically being tested for meningeal irritation signs.

Nasal fluids were examined with $\beta_{2}$ transferrin and glucose to confirm CSF. All the cases underwent brain MRI and CT. CT Cisternography was performed in four cases (25\%) since the exact leakage area or bone defect could not be detected with conventional CT or MRI.

Technique for CT cisternography: After lumbar puncture with a 22 gauge needle, 5-10 $\mathrm{ml}$ iodinated nonionic low osmolar contrast agent (lopamiro $₫ 300$, Bracco, Milan, Italy) was instilled into the thecal sac. The cases were tilted to Trendelenburg position for 60 seconds and imaged with a CT scanner in prone position. The CT scan was performed with thin slices, employing maneuvers that can provoke an active CSF leak such as coughing. The area with a $50 \%$ or more increased $\mathrm{HU}$ value was accepted as the leakage site.

The surgical approach was carried out through the defective side. The pterional or bicoronal craniotomy was performed. The defect was explored and repaired using the galea (in 7 cases) or the galea with collagen matrix (DuraGen®, Integra Life Sciences Corporation. Plainsboro, NJ, USA) (in 5 cases) and in all of the cases the procedure was supported with additionally applied fibrin glue (Tisseel $®$ Baxter Health Care Corporation, Deerfield, IL, USA).

\section{- RESULTS}

Preoperative assessments showed significantly decreased olfaction in 10 cases and nearly complete loss of olfaction in two cases with bilateral nerve atrophy. Otherwise, the neurologic examinations were normal. There was no fever or meningeal irritation signs in any of the cases. However, two cases had a history of treatment for recurrent meningitis before admission. The postoperative follow-up period ranged from 6 to 57 months (mean 23.4 months). There was no postoperative rhinorrhea in any of the cases.
There was a complete correlation between the area where the $\mathrm{HU}$ increased more than $50 \%$ in CT cisternography and the defective area detected during the surgery. There were no complications related either to cisternography such as arachnoiditis or to craniotomy. However, there was a cosmetic problem secondary to craniotomy in the long-term followup. Some of the patients suffered from problems related to temporal muscle atrophy, scar tissue formation and hair loss in the incision line.

Demonstrative cases are presented with Figures 1A, B; 2A, B; $3 \mathrm{~A}-\mathrm{C}$ and all the cases are summarized in Table $\mathrm{I}$.

Case 2 was a 42-year-old woman, who had had an 8-month history of salt-water drainage from her left nostril when standing and postnasal drainage when lying. The images showed the CSF leak, neighbouring left lateral crista galli and its continuity within the nasal cavity (arrows) (Figure 1). While the density of soft tissue in the nasal cavity neghboring this localization was $20 \mathrm{HU}$ in precontrast CT, it was measured $140 \mathrm{HU}$ in the postcontrast CT. A dura defect under the left olfactory nerve was detected during the skull base exploration with left pterional craniotomy by means of a neuro-navigation. The olfactory nerve was seen to be atrophic; specifically in its exit from the cranial cavity. The defect was repaired intradurally by galea graft, fibrin glue and collagen matrix. The case was discharged without any rhinnorhea.

Case 3 was a 47-year-old woman whose complaints started one year ago and disappeared following repeated LPs but recurred a few months later. She had a right nasal discharge. On the right side of cribriform plate (arrows), a leak was detected (Figure 2). A frontobasal approach was performed with bicoronal incision. The right olfactory nerve was quite atrophic. The defect was repaired with galea and fibrin glue.

Case 4 was a 21-year-old man, who had bilateral nasal drainage for 2 months. The patient had cranial MRI and CT cisternography. CSF leak was detected on both sides of cribriform plate (arrows) (Figure 3). A frontobasal approach with bicoronal incision was performed. It was observed that the arachnoid had progressed towards the hole in the cribriform plate and made up a tract towards the ethmoid sinus. Both olfactory nerves were atrophic. Granulation tissues around the olfactory nerves and the olfactory nerves were removed. The defect was repaired using galea, and fibrin glue.

\section{- DISCUSSION}

Unlike traumatic or post-operative leaks, pneumocephalus and deterioration of olfactory functions are rare in spontaneous CSF leaks, though there is a tendency for a prolonged CSF leak. While the CSF leak stops generally within a week in $70 \%$ of the cases in traumatic types, this ratio is only $33 \%$ in spontaneous CSF leaks. The recurrence rate following surgical repair in spontaneous CSF leaks is very high (25$87 \%)$. The most dangerous complication of rhinorrhea is meningitis $(4,12,19,23,29)$. A CSF leak lasting longer than a week does not generally heal spontaneously; hence, surgical treatment becomes obligatory to prevent such complications as meningitis and brain abscess $(2,17,26)$. 
Even though none of the cases in our study had brain abscess, two had history of meningitis. All cases had long-lasting complaints (20 days to 4 years). The CSF leak was generally seen on the posterior and lateral wall of cribriform plate and sphenoid sinuses $(9,12,29)$. The cribriform plate is the most fragile part of calvarium, where the dura clings to the bone very tightly (11). This is the reason why CSF leaks frequently originate at this site.

Long lasting increased intracranial pressure and even normal cerebrospinal fluid pulsation may result in cortical erosion in the weak spots of the anterior and lateral parts of skull base, dural tearing, followed by fistula formation. Some spontaneous CSF leak cases have developed in this way and mostly no other causes could be detected $(8,13,14,22)$.

O'Connell (16) declared that only the arachnoid, the dura and the nasal mucosa constitute the distinction between subarachnoid distance in the orifices of cribriform plates (around nerve fibers) and in the nasal cavity. They also declared that olfactory bulb and frontal lobe, being situated on the cribriform plate, protect this area from the pulsatile effects of CSF, thereby inhibiting the formation of a CSF leak. However, atrophy in the olfactory bulb or any deformity on
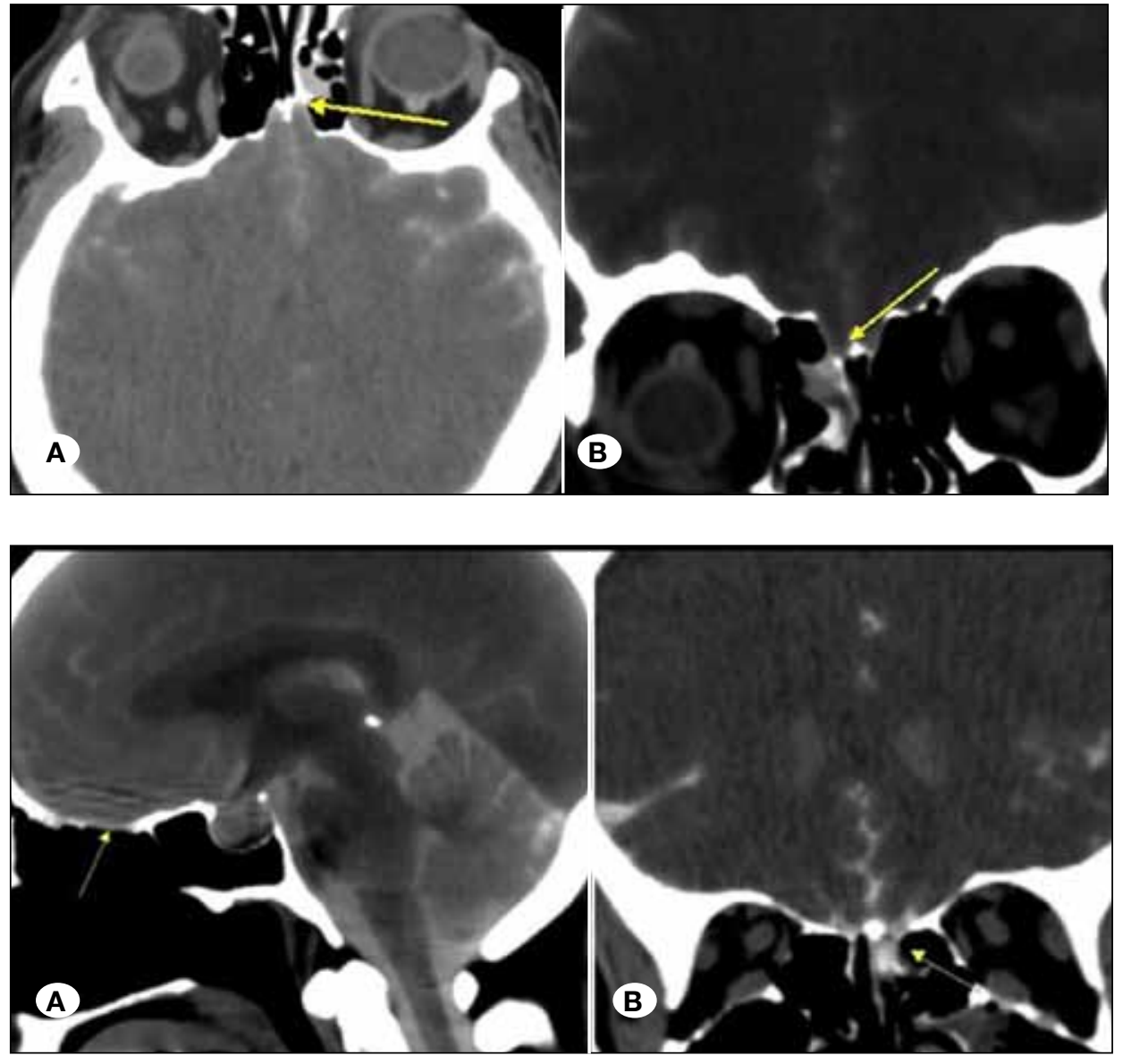

Figure 1: Axial (A) -coronal (B) CT images demonstrate CSF leak, neighbouring crista galli left lateral and showing continuity with nasal cavity.
Figure 2: Sagittal (A) and coronal (B) CT images showing a leak on the right side of cribriform plate.
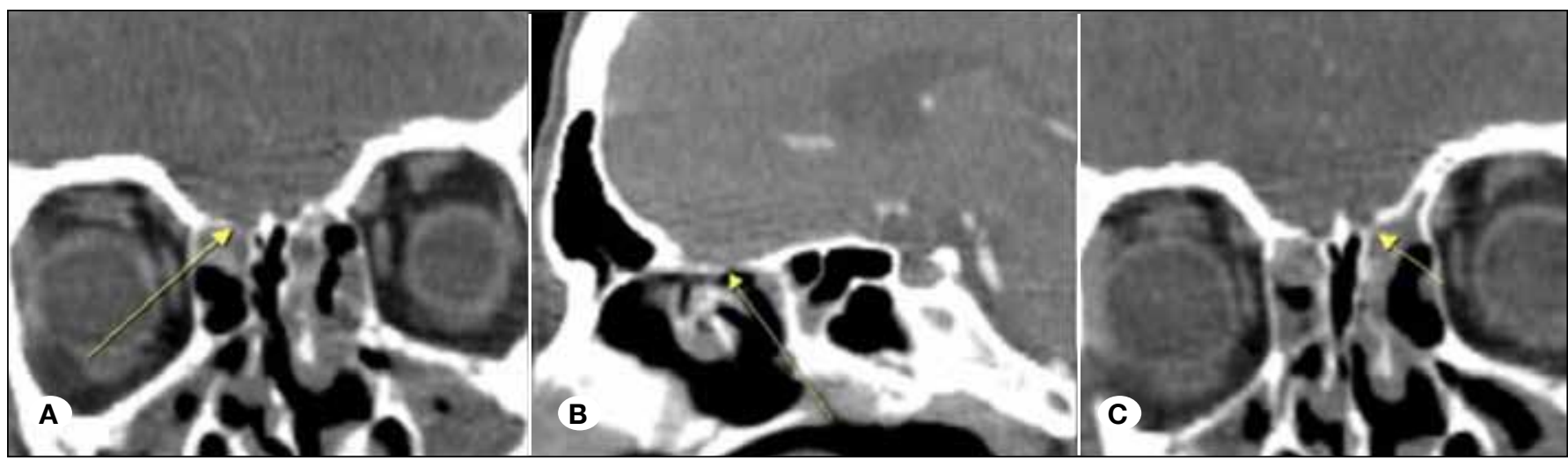

Figure 3: Coronal (A), sagittal (B) and coronal (C) CT images showing a leak on both sides of cribriform plate. 
Table I: Symptoms and Durations, HU Value, Surgical Procedures, CT Cisternography and Peroperative Findings, Surgical Procedures

\begin{tabular}{|c|c|c|c|c|c|c|}
\hline No & $\begin{array}{l}\text { Age } \\
\text { (years)/ } \\
\text { Sex }\end{array}$ & $\begin{array}{l}\text { Rhinorrhea } \\
\text { Side/ } \\
\text { Duration }\end{array}$ & $\begin{array}{l}\text { CT Cisternography } \\
\text { findings }\end{array}$ & $\begin{array}{l}\text { Pre/Postcont } \\
\text { HU value }\end{array}$ & Surgical procedures & Peroperative findings \\
\hline 2 & $42 / F$ & L/8 months & $\begin{array}{l}\text { A leak on the crista galli } \\
\text { left lateral }\end{array}$ & $20 / 140$ & $\begin{array}{l}\text { Left PC, galea +fibrin } \\
\text { glue+collagen matrix }\end{array}$ & $\begin{array}{l}\text { Dural defect around crista galli } \\
\text { and under left } 1^{\text {st }} \text { nerve, nerve is } \\
\text { atrophic }\end{array}$ \\
\hline 3 & $47 / F$ & $\mathrm{R} / 4$ years & $\begin{array}{l}\text { Bone and dural defect on } \\
\text { the right CP level }\end{array}$ & $25 / 150$ & $\mathrm{BC}$, galea +fibrin glue & $\begin{array}{l}\text { Right } 1^{\text {st }} \text { nerve is atrophic, a } \\
\text { leak was around the nerve }\end{array}$ \\
\hline 4 & 21/M & $\begin{array}{l}\text { Bilateral/2 } \\
\text { months }\end{array}$ & $\begin{array}{c}\text { Bilateral bone and dural } \\
\text { defect on the right } \mathrm{CP} \\
\text { level }\end{array}$ & $25 / 130$ & $\mathrm{BC}$, galea +fibrin glue & $\begin{array}{l}\text { Both } 1^{\text {st }} \text { nerve atrophic, } \\
\text { granulation around the nerves }\end{array}$ \\
\hline 6 & $39 / \mathrm{M}$ & $\mathrm{R} / 4$ months & $\begin{array}{l}\text { Dural defect on the right } \\
\text { CP level }\end{array}$ & $28 / 77$ & $\begin{array}{l}\text { Right PC, galea +fibrin } \\
\text { glue+collagen matrix }\end{array}$ & Dural defect under left $1^{\text {st }}$ nerve \\
\hline 7 & $53 / F$ & $\mathrm{R} / 2$ months & $\begin{array}{l}\text { Bone and dural defect on } \\
\text { the right CP level }\end{array}$ & $30 / 113$ & $\mathrm{BC}$, galea +fibrin glue & $\begin{array}{l}\text { Multiple dural defects under left } \\
\qquad 1^{\text {st }} \text { nerve }\end{array}$ \\
\hline 8 & $35 / F$ & $\mathrm{~L} / 1$ year & $\begin{array}{c}\text { Dural defect on the left CP } \\
\text { level }\end{array}$ & $18 / 96$ & $\mathrm{BC}$, galea+fibrin glue & $\begin{array}{l}\text { Dural defect on the cribriform } \\
\text { plate }\end{array}$ \\
\hline 9 & $50 / \mathrm{M}$ & $\mathrm{R} / 11$ months & $\begin{array}{l}\text { Dural defect on the right } \\
\text { CP level }\end{array}$ & $21 / 72$ & $\begin{array}{l}\text { Right PC, galea +fibrin } \\
\text { glue+ collagen matrix }\end{array}$ & Dural defect under left $1^{\text {st }}$ nerve \\
\hline 10 & $56 / F$ & $\mathrm{R} / 7$ months & $\begin{array}{l}\text { Bone and dural defect on } \\
\text { the right } \mathrm{CP} \text { level }\end{array}$ & $39 / 105$ & $\begin{array}{l}\mathrm{BC}, \text { galea }+ \text { fibrin glue }+ \\
\text { collagen matrix }\end{array}$ & $\begin{array}{l}\text { Large dural defect on the } \\
\text { cribriform plate, } 1^{\text {st }} \text { nerve is } \\
\text { bilateral atrophic }\end{array}$ \\
\hline
\end{tabular}

M: Male, F: Female, L: Left, R: Right, CP: Cribriform plate, PC: Pterional craniotomy, BC: Bicoronal craniotomy.

the skull base would bring this natural protection to an end, leading to a CSF leak. To support this hypothesis, we found olfactory nerve atrophy in six cases during exploration.

Having determined the nasal flow to be CSF, the next step is to determine the exact place of the leak, for which radiological imaging plays a critical role. Especially in cases with intermittent leak during inactive periods, it may be problematic to determine the exact leakage site (6). Among the many techniques, CT cisternography stands out as an old but reliable way to detect the leakage and its location. Its main advantage comes from its high contrast contribution to air particularly in paranasal sinuses (15). CT cisternography can be performed when the other diagnostic procedures cannot be performed or are insufficient. A positive CT cisternography can be determined with a direct demonstration of the defect on the skull base or with the opacification in the nasal cavity, the sinuses or the middle ear. If increased contrast is not observed as expected, then the HU measurements of the area are used from both pre and post-contrast series, where an increased $\mathrm{HU}$ of $50 \%$ or more is accepted as positive (25). In our series, even though the exact place of the defect was not shown in some cases, increased $\mathrm{HU}$ value seemed satisfactory for the surgical plan. The site of rhinorrhea was associated with the site where the defect existed. In cribriform plate defects, the surgical procedures should be performed at the side of rhinorrhea.

The treatment of CSF leak has always been an important surgical issue. The first surgical repair and study to determine the leak radiologically was performed by Dandy, who performed a fistula repair with frontal craniotomy in 1926 (3). While Dohlman performed a fistula repair using the first extracranial approach with naso-orbital incision in 1948, the first endoscopic surgical operation was carried out by Wigand in 1981 (5). Nowadays, many authors suggest 
endoscopic repair in the surgical treatment of rhinorrhea due to its higher success rates, lower complication rates and minimally invasive nature (27). Unfortunately, the cases in our series belonged to a period when we did not have enough experience with endoscopic repairs. Despite the possibility of high mortality and morbidity rates and relatively low success rates with surgical treatments, there have been some studies with high success rates $(21,24,26)$. We had no mortality or morbidity in our series. The reason why we did not encounter any complications can be explained by the precise application of microsurgical techniques and meticulous care during the pre-operative and post-operative period.

In surgical treatment, repair of the defect is of vital importance and a number of intra- and extra-cranial approaches have been described; however, in all of these approaches, autogenous grafts like fat, muscle and fascia have been used with no remarkable difference of success rates among them. We found no difference of outcome between the use of autogenous grafts and the use of autogenic grafts along with Duragen $\circledast$. The results were promising in both techniques.

\section{CONCLUSION}

CT cisternography was very effective in detecting the CSF leak and demonstrating the site of the defect. Although endoscopic treatment has been accepted as gold standard in the repair of spontaneous CSF leak in the recent years, treatment via craniotomy is still performed in many centers. Conventional surgery is very succesful in the treatment of rhinorrhea but it is cosmetically problematic. Since there is no difference between the outcomes of the cases in which allografts with autogenous grafts or only autogenous grafts were used, except for specific indications such as CSF leak resulting from multiple large defects. The use of only autogenous grafts with fibrin glue would be recommended to repair the defects.

\section{- REFERENCES}

1. Aarabi B, Leibrock LG: Neurosurgical approaches to cerebrospinal fluid rhinorrhea. Ear Nose Throat J 71:300-305, 1992

2. Abuabara A: Cerebrospinal fluid rhinorrhea: Diagnosis and treatment. Med Oral Patol Cir Bucal 12:e397-400, 2007

3. Briggs RJ, Wormald PJ: Endoscopic transnasal intradural repair of anterior skull base cerebrospinal fluid fistulae. J Clin Neurosci 11: 597-594, 2004

4. Eljamel MS, Foy PM: Nontraumatic CSF fistulae: Clinical history and management. Br J Neurosurg 5:275-279, 1991

5. Faroog MU, Ansari MA: Cerebrospinal fluid rhinorrhea: Etiology site of leakage and endoscopic management. J Coll Phys Surg Pakistan 21:460-463, 2011

6. Hofmann E, Behr R, Schwager K: Imaging of cerebrospinal fluid leaks. Clin Neuroradiol 19:111-121, 2009

7. Hubbard JL, Mc Donald TJ, Pearson BW, Laws ER Jr: Spontaneous cerebrospinal fluid rhinorrhea: Evolving concepts in diagnosis and surgical management based on the Mayo clinic experience from 1970 through 1981. Neurosurgery 16:314-321, 1985

8. Kim CH, Chung SK, Dhong HJ, Lee Jl: Cerebrospinal fluid leakage after gamma knife radiosurgery for skull base metastasis from renal cell carcinoma: A case report. Laryngoscope 118:19251927, 2008

9. Kirtane MV, Gautham K, Upadhyaya SR: Endoscopic CSF rhinorrhea closure: Our experience in 267 cases. Otolaryngol Head Neck Surg 132: 208-212, 2005
10. Lai SY, Kennedy DW, Bolger WE: Sphenoid encephaloceles: Disease management and identification of lesions within the lateral recess of the sphenoid sinus. Laryngoscope 112:18001805, 2002

11. Lantz EJ, Forbes GS, Brown ML, Laws Jr ER: Radiology of cerebrospinal fluid rhinorrhea. AJR 135:1023-1030, 1980

12. Lindstrom DR, Toohill RJ, Loehrl TA, Smith TL: Management of cerebrospinal fluid rhinorrhea: The medical college of Wisconsin experience. Laryngoscope 114:969-974, 2004

13. Lloyd KM, Del Gaudio JM, Hudgins PA: Imaging of skull base cerebrospinal fluid in adults. Radiology 248:725-736, 2008

14. Mirza S, Thaper A, Mc Clelland L, Jones NS: Sinonasal cerebrospinal fluid leaks: Management of 97 patients over 10 years. Laryngoscope 115:1774-1777, 2005

15. Naidich TP, Moranch CJ: Precise anatomical localization of a traumatic sphenoethmoidal cerebrospinal fluid rhinorrhea by metrizamide CT cisternography. J Neurosurg 53:222-228, 1980

16. O'Connell JE: Primary spontaneous cerebrospinal fluid rhinorrhea. J Neurol Neurosurg Psychiatry 27:241-246, 1964

17. Panda NK, Reddy ECE, Bapuraj RJ: CT cisternography in cerebrospinal fluid rhinorrhea: Could it have a therapeutic role? Indian J Otolaryngol Head Neck Surg 57:150-152, 2005

18. Papadea C, Schlosser R: Rapid method for beta 2 transferrin in cerebrospinal fluid leakage using an automated immunofixation electrophoresis system. Clin Chem 51:464-470, 2005

19. Schlosser RJ, Wilensky EM, Grady MS, Palmer JN, Kennedy DW, Bolger WE: Cerebrospinal fluid pressure monitoring after repair of cerebrospinal fluid leaks. Otolaryngol Head Neck Surg 130:443448, 2004

20. Schlosser RJ, Woodworth BA, Wilensky EM, Grady MS, Bolger WE: Spontaneous cerebrospinal fluid leaks: A variant of benign intracranial hypertension. Ann Otol Rhinol Laryngol 115:495-500, 2006

21. Scholsem M, Scholtes F, Collignon F, Robe P, Dubuisson A, Kaschten B: Surgical management of anterior cranial base fractures with cerebrospinal fluid fistulae. Neurosurgery 62:463469, 2008

22. Schuknecht B, Simmen D, Briner HR, Holzmann D: Nontraumatic skull base defects with spontaneous CSF rhinorrhea and arachnoid herniation: Imaging findings and correlation with endoscopic sinus surgery in 27 patients. Am J Neuroradiol 29: 542-549, 2008

23. Shapiro SA, Scully T: Closed continuous drainage of cerebrospinal fluid via a lumbar subarachnoid catheter for treatment or prevention of cranial/spinal cerebrospinal fluid fistula. Neurosurgery 30:241245, 1992

24. Silva LR, Santos RP, Zymberg ST: Endoscopic endonasal approach for cerebrospinal fistulae. Minim Invasive Neurosurg 49: 88-92, 2006

25. Stone JA, Castillo M, Neelon B, Mukherji SK: Evaluation of CSF leaks: High resolution CT compared with contrast enhanced CT and radionuclide cisternography. Am J Neuroradiol 20:706-712, 1999

26. Tosun F, Gonul E, Yetiser S, Gerek M: Analysis of different surgical approaches for the treatment of cerebrospinal fluid rhinorrhea. Minim Invasive Neurosurg 48:355-360, 2005

27. Virk JS, Elmiyeh B, Saleh HA: Endoscopic management of cerebrospinal fluid rhinorrhea: The charing cross experience. $J$ Neurol Surg B 74:61-67, 2013

28. Warnecke A, Averbeck T, Wurster $U$, Harmening $M$, Lenarz $\mathrm{T}$, Stover T: Diagnostic relevance of beta 2 transferrin for the detection of cerebrospinal fluid fistulas. Arch Otolaryngol Head Neck Surg 130:1178-1184, 2004

29. Wax MK, Ramadan HH, Ortiz O, Wetmore SJ: Contemporary management of cerebrospinal fluid rhinorrhea. Otolaryngol Head Neck Surg 116:442-449, 1997 